\title{
Neuroendocrine effects of L-tryptophan and dexamethasone
}

\author{
Lil Träskman-Bendz, Roger F. Haskett, and Athanasios P. Zis \\ Department of Psychiatry, University of Michigan, Ann Arbor, MI 48109, USA
}

\begin{abstract}
An infusion of L-tryptophan was administered twice to five healthy male volunteers, once after pretreatment with dexamethasone $1 \mathrm{mg}$ the previous evening and once after no dexamethasone. Cortisol, prolactin, and growth hormone levels were measured, and the responses to L-tryptophan were compared with those seen after an infusion of L-threonine. L-tryptophan did not produce cortisol secretion after dexamethasone, but prolactin and growth hormone responses were noticed. The results demonstrate a stimulatory effect of L-tryptophan on prolactin and growth hormone secretion, and the former is facilitated by pretreatment with dexamethasone.
\end{abstract}

Key words: Tryptophan - Dexamethasone - Prolactin Growth hormone - Cortisol

Biological studies of depressed patients have mainly focused on two different areas of dysfunction: the monoamine neurotransmitters (Schildkraut 1965; Lapin and Oxenkrug 1969) and the hypothalamo-pituitary neuroendocrine systems (for overviews, see Carroll 1978; Weiner and Ganong 1978; Ettigi 1979). Although there is much evidence for neurotransmitter involvement in the regulation of neuroendocrine function, the precise relationship between these two systems in humans remains poorly defined (Smythe 1977; Meites and Sonntag 1981).

The indoleamine serotonin appears to function as an excitatory neurotransmitter for the secretion of prolactin and growth hormone. Increases in the circulating levels of these pituitary hormones have been consistently reported after the administration of the serotonin precursors L-tryptophan or 5-hydroxytryptophan to normal controls (for overviews, see Wirtz-Justice 1977; Charney et al. 1982). The role of serotonin on the hypothalamo-pituitary-adrenal axis is not clear. Circulating cortisol levels have shown variable responses to serotonergic precursors in control subjects (Imura et al. 1973; Wirtz-Justice et al. 1976; Woolf and Lee 1976; Hyppää et al. 1979).

The present investigation was conducted to further examine the role of serotonin in the regulation of neuroendocrine systems. We administered L-tryptophan to healthy subjects and compared the hormonal responses to those seen after $\mathrm{L}$-threonine. L-Threonine is not a neurotransmitter precursor, although an interactive effect on L-trypto-

Offprint requests to: L. Träskman-Bendz, Department of Psychiatry, Karolinska Hospital, S-10401 Stockholm, Sweden phan transport across the blood-brain barrier has been demonstrated (Oldendorf and Szabo 1976; Yuwiler et al. 1977; Pratt 1979). This may reduce the serotonin synthesis. We also examined the effect of a single dose of dexamethasone on the hormonal response to L-tryptophan.

\section{Materials and methods}

This study was performed with five healthy male volunteers, aged 19-33 years, who gave informed consent, were medication-free and had no history of significant physical or psychiatric illness. Each subject was admitted on three occasions to the Clinical Research Center at the University of Michigan. Subjects arrived during the evening, and fasted and remained supine after midnight. At 7:30 a.m. an IV catheter was inserted and kept patent with heparinized saline. L-Tryptophan $5 \mathrm{~g}$ or $2.9 \mathrm{~g}$ L-threonine (equimolar dosage) was diluted in $0.45 \%$ normal saline with $50 \% \mathrm{NaOH}$ added to bring the solution to $\mathrm{pH} 7.4$ (see Charney et al. 1982). The infusion began at 9:30 a.m. and was administered over $20 \mathrm{~min}$.

At the first two admissions each subject received dexamethasone $1 \mathrm{mg}$ at 11:30 p.m., $10 \mathrm{~h}$ prior to the infusion of either L-tryptophan or L-threonine in a randomly assigned double-blind design. During the third admission pretreatment with dexamethasone was omitted and all subjects received L-tryptophan. The mean interval between the admissions was 13.6 days (range 6-35) and 29.4 days (range 14-44), respectively. Blood samples were drawn at -30 , $0,+40,+50,+60,+90,+120,+180 \mathrm{~min}$, where 0 denotes the start of the infusion. All plasma samples from a single subject were analyzed in the same assay.

Plasma prolactin was measured by an established double antibody radioimmunoassay technique (Sinha et al. 1973). The antibody and primary standard were kindly donated by the NIH National Pituitary Agency and prepared by Dr AF Parlow of Harbour General Hospital, Torrance, California. The assay sensitivity range was $0.5-200.0 \mathrm{ng} / \mathrm{ml}$. Total plasma corticoids ("cortisol") were measured by the transcortin method of Murphy (1967). Growth hormone measurement utilized a radioimmunoassay supplied by Serono.

Blood pressure and heart rate were recorded every $10 \mathrm{~min}$. Each subject recorded their experience of specific symptoms on $100 \mathrm{~mm}$ line visual analogue scales. The symptoms were: mood, pain, inner tension, drowsy/alert, nausea, irritability, strange feeling (to be specified).

Changes in circulating levels of hormones over time 
were examined with a repeated measures analysis of variance (ANOVA) that included all time-points of the volunteers' data. We performed two separate analyses of the data. The effect of an L-tryptophan infusion after dexamethasone pretreatment was compared with an infusion of $\mathrm{L}$-threonine under similar conditions. This utilized the mean plasma hormone levels as the repeated measure and the infused amino acid as the grouping factor. The effect of dexamethasone pretreatment on the hormonal response to an infusion of L-tryptophan was examined using the mean plasma hormone levels as the repeated measure, with the presence or absence of dexamethasone pretreatment as the grouping factor.

\section{Results}

Figures 1-3 show the mean values for plasma cortisol prolactin, and growth hormone associated with each of the three infusions.

The plasma prolactin level showed a significant main effect for time in both analyses (L-tryptophan, L-threonine; $F=2.56, d f=6,24, P=0.046$; dexamethasone, no dexamethasone; $F=4.58, d f=6.24, P=0.003)$. Although the group effect was not significant $(F=4.88, d f=1,4$, NS; $F=3.88$, $d f=1,4$, NS, respectively), the amino acid by time interaction was significant $(F=5.05, d f=6,24, P=0.002)$ and reflects the different response of plasma prolactin levels after L-tryptophan compared with L-threonine. The dexamethasone pretreatment by time interaction was not significant, suggesting that dexamethasone did not significantly alter the pattern of prolactin response to L-tryptophan.

Analyses of the mean plasma cortisol levels after the infusions revealed no significant time or group effect, suggesting that this hormone did not respond consistently to either amino acid. The response to L-tryptophan was also unchanged by pretreatment with dexamethasone.

Although the analysis of mean growth hormone levels after L-tryptophan and L-threonine did not reveal a significant time or group effect, the amino axid $X$ time interaction was highly significant ( $F=4.86, d f=6,24, P=0.002$ ). There

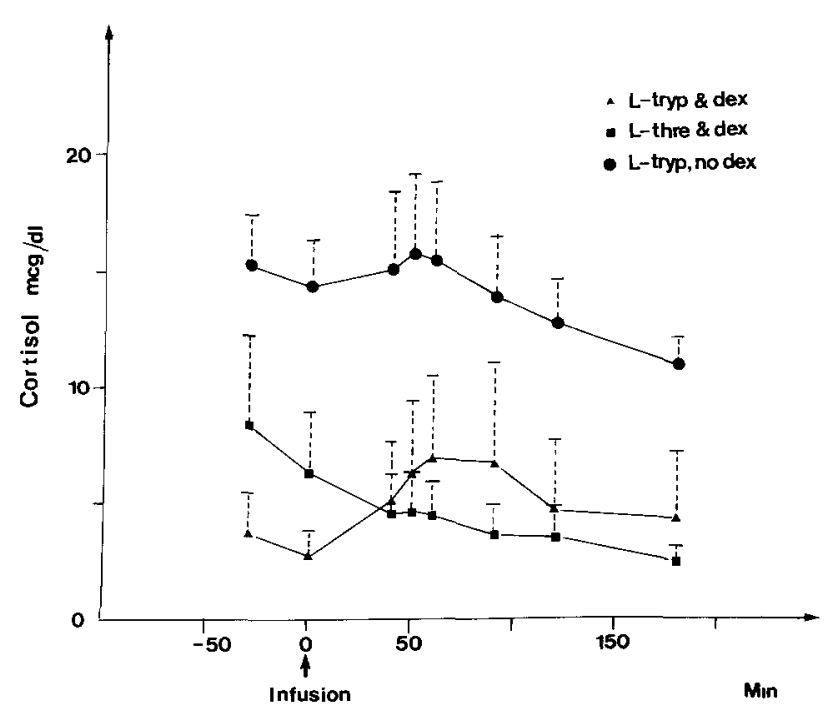

Fig. 1. Effect of IV L-tryptophan or L-threonine with previous dosage of dexamethasone or L-tryptophan alone on cortisol. Each point represents mean $\pm S E$ was no significant effect of dexamethasone pretreatment, and although the time effect was highly significant $(F=9.50$, $d f=6,24, P=0.000$ ), the dexamethasone pretreatment by time interaction was not significant.

The individual baseline and peak-levels of prolactin and growth hormone are shown in Figs. 4 and 5. These figures also demonstrate that four of five subjects had the following response patterns for prolactin: no response after L-threonine, but an increase after L-tryptophan, which was enhanced by dexamethasone pretreatment the previous evening.

Side-effects. No symptoms were reported after L-threonine. The most common symptoms associated with the L-tryptophan infusion were drowsiness, irritability and strange feelings, described as "lightheadedness", "dizziness", "lousiness", "tipsy, like after a couple of drinks" and "numbness

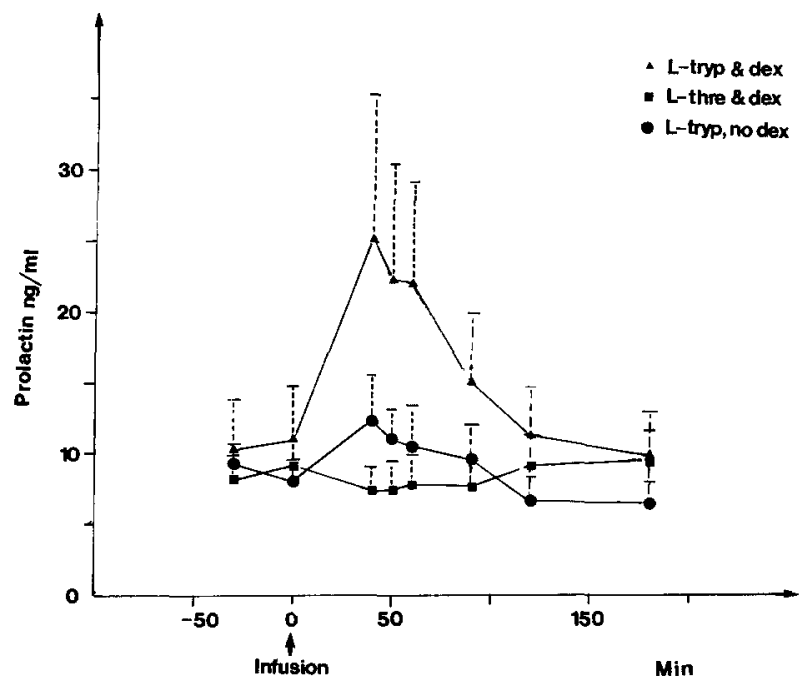

Fig. 2. Effect of IV L-tryptophan or L-threonine with previous dosage of dexamethasone or L-tryptophan alone on prolactin. Each point represents mean $\pm S E$

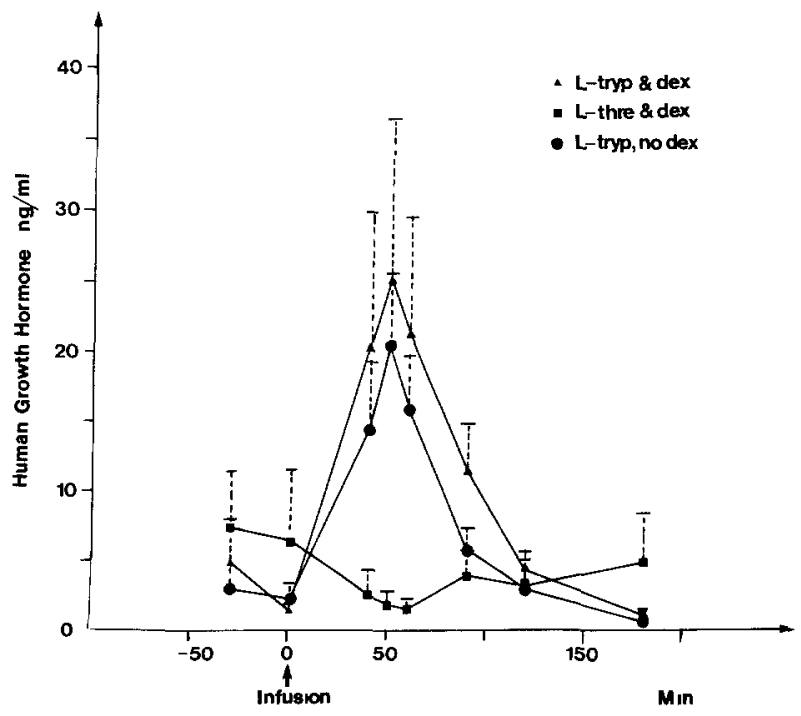

Fig. 3. Effect of IV L-tryptophan or L-threonine with previous dosage of dexamethasone or L-tryptophan alone on growth hormone. Each point represents mean $\pm \mathrm{SE}$ 
1

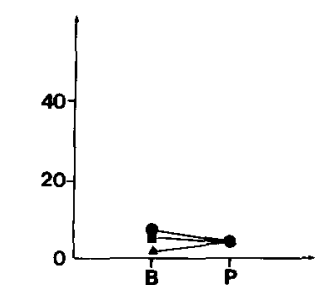

III

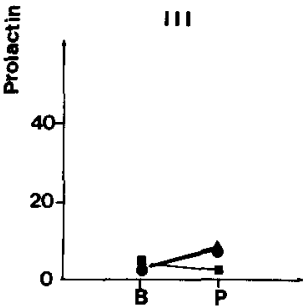

I

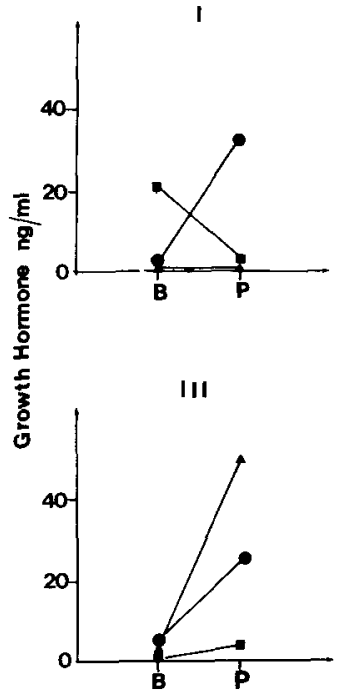

II

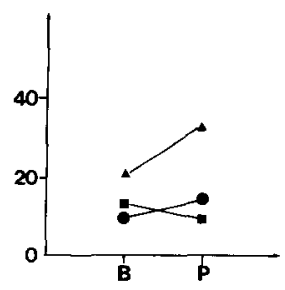

IV

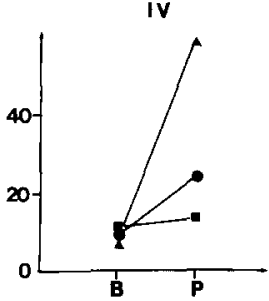

II

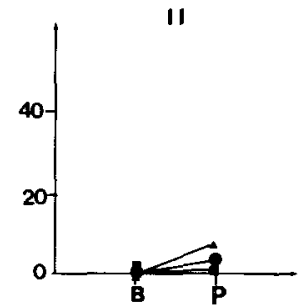

IV

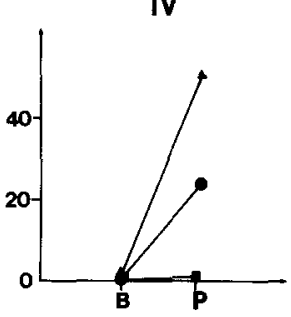

- L-tryp \& dex

- L-thre \& dex

- L-tryp, no dex

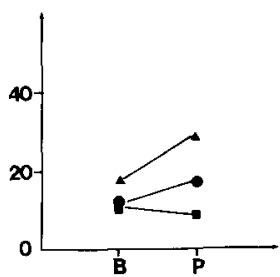

- L-tryp \& dex

- L-thre \& dex

- L-tryp, no dex above eyebrows". The subject who complained of the most side-effects also had the most prominent neuroendocrinological responses. In four out of five subjects the maximum severity of side-effects occurred between $\mathbf{1 5}$ and $\mathbf{3 0}$ min after the start of the L-tryptophan infusion, and they all preceded the peak effects of hormones by $25.6 \pm 10.2 \mathrm{~min}$.

The vital signs were stable before, during and $1 \mathrm{~h}$ after the infusions.

\section{Discussion}

The findings in this study indicate that L-tryptophan stimulates the secretion of growth hormone and prolactin, but not cortisol, both with and without a previous dosage of dexamethasone. Other studies with L-tryptophan given IV to healthy subjects have shown similar increases of prolactin and growth hormone (MacIndoe and Turkington 1973; Charney et al. 1982; Heninger et al. 1984). Cortisol was measured in only one study during L-tryptophan infusion (Woolf and Lee 1976), and decreased levels were reported.

L-Tryptophan is almost exclusively metabolized in the serotonergic nerve-ending, which selectively contains tryp- tophan hydroxylase (Moir and Eccleston 1968; Aghajanian and Asher 1971; Fuxe et al. 1971). Therefore, the endocrine responses that were observed in our study may have resulted from either the direct action of L-tryptophan or increased levels of its metabolite serotonin. It is also possible that the glucocorticoid dexamethasone exerts its facilitatory effects on the prolactin and growth-hormone systems via changes in serotonergic functioning. Millard et al. (1972) reported that IV administration of $\mathrm{L}$-tryptophan to rats produced an increase in cerebral serotonin levels, and this increase was doubled by prior administration of corticosterone. Banki et al. (1983) found increased levels of the serotonin-metabolite 5-hydroxyindoleacetic acid (5-HIAA) in cerebrospinal fluid after dexamethasone in a group of psychiatric patients. Similarly, Rothschild et al. (1985) reported increased serotonin and 5-HIAA levels in the hypothalamus of rats after one dosage of dexamethasone IP.

The mechanism by which prior administration of dexamethasone enhances prolactin and growth hormone responses to L-tryptophan may be similar to the observed increase in the prolactin-response to a single dosage of haloperiodol after dexamethasone-pretreatment (Aylsworth 
et al. 1980). Although the enhancing effect of dexamethasone could be the result of additional dopamine blockade, this phenomenon would also be consistent with a serotonergic effect of dexamethasone. By comparison, prolactin and ACTH-responses to morphine and TRH (Rossier et al. 1980; Steger et al. 1981), and stress-induced alterations in prolactin, ACTH and cortisol following insulin (Copinschi et al. 1975) or foot-shocks (Rossier et al. 1980), were blunted or unchanged by dexamethasone pretreatment.

The design of this study does not permit us to exclude an order effect with the reduction of prolactin response to the infusion resulting from increased familiarity with the procedure. There is, however, no significant difference between trials in the preinfusion levels of prolactin.

In conclusion, our study supports the involvement of the serotonergic system in the regulation of prolactin and growth-hormone secretion, and suggests that elevated glucocorticoid levels can enhance this stimulatory input.

Acknowledgements. This study was supported by Public Health Service Grant \#MH28294. Dr BJ Carroll advised in the design of this study and Connie Corson, MD, provided invaluable assistance during its implementation.

\section{References}

Aghajanian GK, Asher IM (1971) Histochemical fluorescence of raphe neurons: selective enhancement by tryptophan. Science 172:1159-1161

Aylsworth CF, Sylvester PW, Leung FC, Meites J (1980) Inhibition of mammary tumor growth by dexamethasone in rats in the presence of high serum prolactin levels. Cancer Res 40:1863-1866

Banki CM, Arato M, Papp Z, Kurcz M (1983) The influence of dexamethasone on cerebrospinal fluid monoamine metabolites and cortisol in psychiatric patients. Pharmacopsychiatria $16: 77-81$

Carroll BJ (1978) Neuroendocrine function in psychiatric disorders. In: Lipton MA, DiMascio A, Killam KF (eds), Psychopharmacology: A generation of progress. Raven Press, New York, pp 487-497

Charney DS, Heninger GR, Reinhard Jr JF, Sternberg DE, Hafstead KM (1982) The effect of intravenous L-tryptophan on prolactin and growth hormone and mood in healthy subjects. Psychopharmacology 77:217-222

Copinschi G, L'Hermite M, Leclerq R, Golstein J, Vanhaelst L, Virasoro E, Robyn C (1975) Effects of glutococorticoids on pituitary hormonal responses to hypoglycemia. Inhibition of prolactin release. J Clin Endocrinol Metab 40:442-449

Ettigi PG (1979) Psychoendocrine correlates in affective disorder. In: Müller EE, Agnoli A (eds), Neuroendocrine correlates in neurology and psychiatry. Elsevier/North Holland Biomedical Press, pp 225-238

Fuxe K, Butcher LL, Engel J (1971) DL-5-Hydroxytryptophaninduced changes in central monoamine neurons after peripheral decarboxylase inhibition. J Pharm Pharmacol 23:420-424

Heninger GR, Charney DS, Sternberg DE (1984) Serotonergic function in depression. Prolactin response to intravenous tryptophan in depressed patients and healthy subjects. Arch Gen Psychiatry $41: 398-402$

Hyppää MT, Jolma T, Liira J, Långvik V-A, Kytömäki O (1979) L-Tryptophan treatment and the episodic secretion of pituitary hormones and cortisol. Psychoneuroendocrinology 4:29-35
Imura H, Nakai Y, Yoshimi T (1973) Effect of 5-hydroxytryptophan (5-HTP) on growth-hormone and ACTH release in man. J Clin Endocrinol Metab 36:204-206

Lapin IP, Oxenkrug GF (1969) Intensification of the central serotonergic processes as a possible determinant of the thymoleptic effect. Lancet I:132-136

MacIndoe JH, Turkington RW (1973) Stimulation of human prolactin secretion by intravenous infusion of L-tryptophan. J Clin Invest 52:1972-1978

Meites J, Sonntag E (1981) Hypothalamic hypophysiotropic hormones and neurotransmitter regulation: current views. Ann Rev Pharmacol Toxicol $21: 295-322$

Millard SA, Costa E, Gal EM (1972) On the control of brain serotonin turnover rate by end product inhibition. Brain Res $40: 545-551$

Moir ATB, Eccleston D (1968) The effects of precursor loading in the cerebral metabolism of 5-hydroxyindoles. $\mathrm{J}$ Neurochem 15:1093-1108

Murphy BEP (1967) Some studies of the protein-binding of steroids and their application to the routine micro and ultramicro measurement of various steroids in body fluids by competitive protein-binding radioassay. J Clin Endocrinol Metab 23:973-990

Oldendorf WH, Szabo J (1976) Amino acid asignment to one of three blood-brain barrier amino acid carriers. Am J Physiol 230:94-98

Pratt OE (1979) Kinetics of tryptophan transport across the bloodbrain barrier. J Neural Transm Suppl 15:29-42

Rossier J, French E, Rivier C, Shibasaki T, Guillemin R, Bloom FE (1980) Stress-induced release of prolactin: Blockade by dexamethasone and naloxone may indicate $\beta$-endorphin mediation. Proc Natl Acad Sci USA 77:666-669

Rothschild AJ, Langlais PJ, Schatzberg AF, Miller MM, Saloman MS, Lerbinger JE, Cole JO, Bird ED (1985) The effects of a single acute dose of dexamethasone on monoamine and metabolite levels in rat brain. Life Sci 36:2491-2501

Schildkraut JJ (1965) The catecholamine hypothesis of affective disorders: a review of supporting evidence. Am J Psychiatry $122: 509-522$

Sinha YN, Selby FB, Lewis UJ, VanderLaan WP (1973) A homologous radioimmunoassay for human prolactin. J Clin Endocrinol Metab 36:509-516

Smythe GA (1977) The role of serotonin and dopamine in hypothalamic-pituitary function. Clin Endocrinol 7:325-341

Steger RW, Silverman AY, Asch RH (1981) Glucocorticoid suppression of pituitary prolactin release in the nonhuman primate. J Clin Endocrinol Metab 53(6): 1167-1170

Weiner GI, Ganong WF (1978) Role of brain monoamines and histamine in regulation of anterior pituitary secretion. Psychol Rev 58:905-976

Wirtz-Justice A, Pühringer W, Lacoste V, Graw P, Gastpar M (1976) Intravenous L-5-hydroxytryptophan in normal subjects: An interdisciplinary precursor loading study. Pharmakopsychiatr 9:277-288

Wirtz-Justice A (1977) Theoretical and therapeutic potential of indoleamine precursors in affective disorders. Neuropsychobiology 3:199-233

Woolf PD, Lee L (1976) Effect of the serotonin precursor, tryptophan, on pituitary hormone secretion. J Clin Endocrinol Metab 45:123-133

Yuwiler A, Oldendorf WH, Geller E, Braun L (1977) Effect of albumin binding and amino acid competition on tryptophan uptake into brain. J Neurochem 28:1015-1023

Received May 21, 1985; Final version November 12, 1985 